\title{
The 5th International Light Metal Technology Conference: An International Tradition Continues
}

\author{
Diran Apelian
}

The motivation for incorporating lightweight materials such as aluminum, magnesium and titanium and their alloys in the transportation sector has always been based on the need to reduce fuel consumption and thereby carbon dioxide emissions. The worldwide debate on climate change and the legislation currently being discussed to tackle emissions can only serve to strengthen this motivation. The challenge is to realize the potential of light metal alloys in competition with other structural material like high strength steel and polymer matrix composites. The goal is to optimize established light metal alloys or to design new alloys to meet the requirements for challenging applications. New drive concepts require a rethinking and modification of structural concepts. The multi-material concept will influence the research and development activities for light metals. The development of new processing technologies and the optimization of processing parameters will play an important role. However, it will also be necessary to develop enabling technologies (e.g., new welding and joining methods that allow the highest specifications for strength to be met). Economy with a maximum level of safety must be guaranteed by the development of comprehensive evaluation methods for materials and components.

The 5th International Light Metal Technology (LMT) Conference was held in Lüneburg, Germany from July 19-22, 2011. The LMT conference is a biennial event; previous LMT conferences that have been held are: Brisbane (Australia) in 2003, St.Wolfgang (Austria) in 2005, Saint-Sauveur
(Canada) in 2007, and the Gold Coast (Australia) in 2009. The Light Metals Alliance (LMA) is an international effort joining eight national scientific organizations that have strong alliances with the industrial sector:

\section{The objective of}

the LMA is to foster

international

collaboration in the

field of research and

technology transfer

pertaining to the use

of light metals.

- CAST - Cooperative Research Centre, Australia

- Austrian Institute of Technology, Light Metal Technologies Ranshofen (LKR)

- CANMET Materials Technology Laboratory, Canada

- Helmholtz-Zentrum Geesthacht, Magnesium Innovation Centre, Germany

- Worcester Polytechnic Institute (USA) - Metal Processing Institute

- Council for Scientific and Industrial Research (South Africa)

- BCAST- Brunel Centre for Advanced Solidification Technology, Brunel University (UK)

- Natl. Engineering Centre of Light Alloy Net Forming, Shanghai Jiao Tong University

\section{(China)}

The objective of the LMA is to foster international collaboration in the field of research and technology transfer pertaining to the use of light metals. Specific areas of interest include alloys and composites of aluminum, magnesium and titanium for applications in transportation industries. Activities of the LMA include:

- Sharing of technical information on a voluntary basis

- Collaborating on research and technology transfer projects

- Seeking funding for collaborative projects

- Exchanging research and technical personnel between labs

- Holding a bi-annual international conference on Light Metals Technology

Helmholtz-Zentrum Geesthacht, one of the 17 members of the Helmholtz Association of German Research Centres, was the organizer of the LMT 2011 conference. For more than one decade, research on magnesium and its alloys has been performed in the Helmholtz Zentrum Geesthacht at the Institute for Materials Research, within the framework of a program to be aimed at the development of novel lightweight structural materials.

The conference was focused on ongoing topics of research in the light metals aluminum, magnesium and titanium, as well as titanium aluminides. Scientific issues such as mechanical properties, corrosion, processing innovations were featured, as well as current applications in aerospace, automotive, and medical sectors. Societal issues regarding environmental challenges and implementation of lightweight mate- 
rials for a renewable energy economy were also addressed. The conference provided an opportunity for researchers and industry members to learn of new developments in light metals technologies and to facilitate collaboration between domestic and international specialists in the field. It was a great opportunity for those involved in the light metals industry to learn about the latest developments in light metals research conducted worldwide.

The LMT conference cuts across conventional S\&T boundaries by concentrating on light metals technology rather than general aspects of metallurgy. The conference focus was on leading edge technologies that are being developed by researchers in cooperation with industry partners. LMT2011 attracted leaders and decision makers from industry, government, universities and public research organizations committed to advancing the application of light metals in everyday life. Representatives from the primary metal, automotive, aerospace, defense, biomedical and research sectors attended the conference to discuss and present on the latest developments in the field.

The conference consisted of one plenary session, 18 parallel sessions and one poster session with 4 plenary lectures, 18 keynote lectures, 94 contributed lectures and 45 posters from 21 countries from five continents. More than 100 presentations gave scientific and industrial insights on developments in aluminum, titanium and magnesium. More than 150 participants from 23 countries participated in the beautiful surroundings of Lüneburg, Germany, a historic and ancient middle age city close to Hamburg.

The plenary session featured four key areas:

- FSW Applied on Mid Size Aircraft, F. Fernandez (São José dos Campos, São Paulo/BR)

- Materials Science and Engineering Opportunities for an Energy Efficient and Low Carbon Economy, D. Apelian (Worcester/USA)

- In Situ Studies of Light Metals With Synchrotron Radiation and Neutrons, A. Schreyer, P. Staron,
A. Stark, F. Pyczak, M. Salgado, N. Hort, H. Eckerlebe, K.U. Kainer, M. Müller (Geesthacht/ DE), T. Lippmann (Hamburg/ DE), F. Beckmann, M. Oehring

- Liquid Metal Engineering of Light Alloys, Z.Y. Fan (Uxbridge/UK)

The sessions covered topics such as: cast alloys; wrought alloys; computational materials science; processing innovations; corrosion and surface treatment; automotive, aerospace and energy applications; biomaterials; microstructure and properties; environmental challenges; and novel forming technologies. The conference proceedings titled: Proceedings of the Fifth International Light Metals Technology Conference 2011 was edited by Hajo Dieringa, Norbert Hort, and Karl Ulrich Kainer. It is Volume 690 of the Materials Science Forum (ISSN 02555476).

Diran Apelian, Howmet Professor of ME, is the Director, Metal Processing Institute, WPI, 100 Institute Road, Worcester, MA 01609 USA; (508) 831-5992; fax (508) 831-5993; e-mail dapelian@ wpi.edu.

ice | science

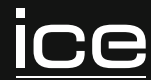

publishing

\section{You're on the verge of making a pioneering new discovery!}

This new flagship journal collection, from ICE Publishing, delivers a truly holistic overview in the areas of materials science, biomaterials, nanotechnology and energy.

Nanomaterials and

Energy

Bringing together research

from scientists and engineers to identify new and ever more efficient energy sources with a cost-benefit focus. Launching January 2012.

\section{Emerging Materials} Research

Uniting researchers across

science and engineering

to identify revolutionary

and diverse applications for

new and evolving materials.

Launching February 2012.
Bioinspired,

Biomimetic and Nanobiomaterials Stimulating the crossfertilisation of ideas, inspired by the natural world, that can be practically and powerfully applied in a wide range of contexts. Launching February 2012.

\section{FREE ONLINE ACCESS}

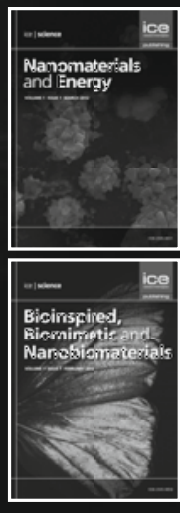

to all published content in 2011 and 2012

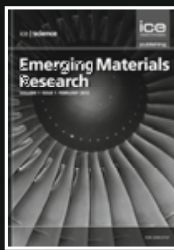

Find out more, visit http://www.icevirtuallibrary.com/info/science For all the latest news: Sign up to the ICE Science email alert: http://academic.icepublishing.com/ps/sciencesignup ICE Science is brought to you by ICE Publishing, with a history of connecting research and practice since 1836. 